\title{
Green Approach to the Synthesis of Poly(Vinyl Alcohol)- Silver Nanoparticles Hybrid Using Rice Husk Extract and Study of its Antibacterial Activity
}

\author{
Pinaki Mandal' ${ }^{1}$,Samaresh Ghosh, ${ }^{1, * \text { (D }}$ \\ 1 Department of Chemistry, Bankura Sammilani College, Kenduadihi, Bankura-722102, West Bengal, India \\ * Correspondence: gsamaresh@yahoo.com;
}

Scopus Author ID 7404807881

Received: 22.04.2020; Revised: 7.05.2020; Accepted: 8.05.2020; Published: 13.05.2020

\begin{abstract}
Green synthesis of silver nanoparticles (AgNPs) using rice husk (RH) as low-cost agricultural waste material has been gaining importance in recent years. Meanwhile, poly (vinyl alcohol) (PVA) is reported to involve in the green production of AgNPs as low-cost, water-soluble, biocompatible and biodegradable stabilizing polymer. The present study is focussed on the green synthesis of poly (vinyl alcohol) (PVA) - silver nanoparticles (PVA-AgNPs) hybrid using rice husk extract as a reducing agent. The results recorded from UV-vis spectrum and transmission electron microscopy (TEM) support the characterization of AgNPs produced. Synthesised PVA-AgNPs hybrid revealed effective antibacterial activity against Escherichia coli and Bacillus sp.
\end{abstract}

Keywords: Silver nanoparticles; poly (vinyl alcohol); green method; rice husk extract; antibacterial.

(c) 2020 by the authors. This article is an open access article distributed under the terms and conditions of the Creative Commons Attribution (CC BY) license (https://creativecommons.org/licenses/by/4.0/).

\section{Introduction}

To date, the development of reliable methods to produce silver nanoparticles (AgNPs) is an important aspect of nanoscience and nanotechnology[1-5]. Owing to their unique physiochemical properties, which differ from those of bulk counterparts, they have attracted considerable interest, particularly in biomedical science as antibacterial agents[6-9]. However, there has been serious concern about their tendency to form agglomerates deteriorating their properties, which limit their use as nanoparticles in the biomedical field. Thus prevention of agglomeration AgNPs by using stabilizing agents has become an

important issue[10]. Recently, efforts have been made on the synthesis of environmental stabilized AgNPs using organic polymers, in particular, chitosan, starch, and poly (vinyl alcohol) (PVA) as stabilizing and supporting agents[11-15]. Further, capped AgNPs possessing abundant functional groups of polymer framework is reported to have enhanced ability to interact with the bacterial cell wall, rich in polysaccharides, phosphatides, and protein. Thus, capped AgNPs have been claimed to exhibit better antibacterial activity than uncapped AgNPs[10,16]. Importantly, PVA has shown to be promising water soluble stabilizing polymer that displays capping properties due to the presence of many hydroxyl groups. The ability to use such water soluble, biodegradable, biocompatible and extremely low cytotoxic polymer to fabricate bionanocomposite would be a significant advance.

Chemical and physical methods are used to produce AgNPs, but these techniques involve the use of hazardous chemicals (reducing, capping and stabilizing agents), high energy 
requirements, harmful UV light or microwave radiation and toxic by-products etc[3]. To overcome the drawbacks of these techniques, it is highly desirable to adopt safer and environmentally friendly alternative methods for obtaining AgNPs. In such a situation, the green synthetic approach utilizing various bio-resources such as microorganisms, plant (flower, leaf, bark, fruit, cereal etc.) extract or plant biomass is a potential environmental friendly alternative for obtaining AgNPs[17-19]. Further, the need for use of AgNPs against microbes in biomedical fields leads to the developing interest in the synthesis of AgNPs in a green environment.

Around 25 mass $\%$ of world annual rice production is the husk, which is generated as a byproduct from the rice milling and agro-based biomass industry and discarded largely as agricultural waste[20]. Rice husk is abundant with a broad variability of bioactive compounds, which make it as reported reducing agent and thus utilization of this resource might be of cheap, sustainable and eco-friendly approach for preparing AgNPs[21].

Taking into account our interest in the biosynthesis of nanostructure materials and inspired by our previous work on the use of reducible bioresources[22], this article reports the green method for synthesis of PVA - silver nanoparticles (PVA-AgNPs) hybrid using rice husk extract and evaluation of its antimicrobial activity against Escherichia coli (E. coli) sp. and Bacillus sp.

\section{Materials and Methods}

\subsection{Preparation of rice husk extract.}

The rice (Oryza sativa L.) husk used in this study was collected from local rice-mill at Bankura, West Bengal. It was then squeezed and ground, passed through $1 \mathrm{~mm}$ sieve, and then stored at $4^{0} \mathrm{C}$ until use. $3 \mathrm{~g}$ of Rice husk was dispersed in deionized water to obtain $10 \%$ aqueous dispersions. Then the dispersion was heated with continuous stirring at $60^{\circ} \mathrm{C}$ for 30 minutes. Subsequently, it was filtered through Whatman No.1 filter paper and the rice husk extract was stored in a deep freezer at $4^{0} \mathrm{C}$ for further experiments.

\subsection{Synthesis of PVA-AgNPs hybrid.}

To achieve the synthesis, initially $0.5 \mathrm{~mL}, 20 \% \mathrm{w} / \mathrm{v}$ aqueous PVA solution (prepared in warm water) was mixed with $4 \mathrm{ml}$ of $0.1 \mathrm{M} \mathrm{AgNO}_{3}$ solution and kept at room temperature for 15 minutes. Then $0.5 \mathrm{~mL}$ of rice husk extract was added and color change was noted. The colorless solution gradually turned to dark brownish after a few hours. After $24 \mathrm{~h}$, the solution was centrifuged to discard minor precipitate produced. The supernatant was collected and mixed well with another $0.5 \mathrm{~mL}, 20 \%$ PVA solution to result in a final solution labeled as PVA-AgNPs hybrid.

\subsection{Characterization of synthesised AgNPs.}

UV-vis spectral analysis was carried out by using Shimadzu UV-visible spectrophotometer (UV-1800). The absorption spectra were taken after diluting a small aliquot of the reaction mixture. Particle sizes of the green synthesized silver nanoparticles were examined using Transmission Electron Microscopy (TEM) with a JEOL JEM1400 plus microscope operating at an accelerated voltage of $120 \mathrm{kV}$. 


\subsection{Antimicrobial Assessment.}

The antibacterial activity of PVA-AgNPs hybrid solution was evaluated against gram negative Escherichia Coli (E. coli) and gram positive bacteria Bacillus sp. by standard agar well diffusion method. Fresh overnight grown bacterial suspension of E. coli and Bacillus sp. were swabbed on the respective petriplates filled with sterile nutrient agar. Then, circular wells were made on each agar plate with the help of a sterile borer. $30 \mu \mathrm{L}$ and $50 \mu \mathrm{L}$ of PVA-AgNPs hybrid solutions (AgNPs conc. $0.07 \mathrm{M}$ ) were placed on wells of agar plates exposed to E. coli and Bacillussp., respectively. The solution of rice husk extract with PVA was employed as a control. All the petriplates were incubated at $37^{\circ} \mathrm{C}$ for 24 hours in bacteriological incubator and the antibacterial activity was indexed by measuring the inhibition zone ( $\mathrm{mm}$ ) around the well. All the experiments were carried out in triplicate and recorded the average inhibition zone.

\section{Results and Discussion}

Recently, phytochemicals mediated synthesis of AgNPs has become attractive due to its eco-friendly nature[4,17-19]. Rice husk is abundant with various phytochemicals, especially phenolic acids, which make it promising bio-reductant for preparing AgNPs[21]. In addition, hydrophilic PVA possessing a number of hydroxyl chelating functional groups was involved as a capping agent for green production of AgNPs in a solution phase. A schematic illustration of the synthetic route is described in Scheme 1.

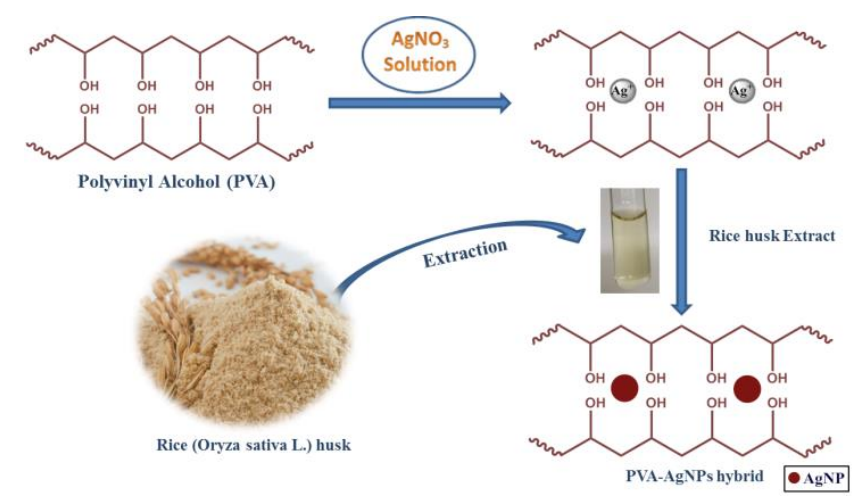

Scheme 1. Synthesis of PVA-AgNPs using rice husk extract.

In this experiment, after the addition of rice husk extract into the mixture containing aqueous solution of $\mathrm{AgNO}_{3}$ and PVA, it was observed that the transparent solution gradually changed color to light yellow and finally became dark- brown as shown in figure 1 . The change is color was due to surface plasmon resonance (SPR) effect of AgNPs as evidenced by the appearance of broad peak around at $435 \mathrm{~nm}$ in the UV-visible spectra (Figure 2).

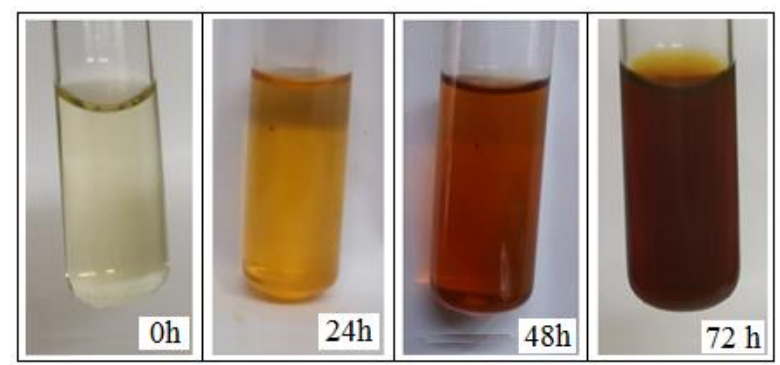

Figure 1. Digital photo of synthesized $\mathrm{AgNPs}$ from a mixture of aqueousPVA, $\mathrm{AgNO}_{3}$ and rice husk extract at different time intervals. 
.As also evident from Figure 1, the intensity of color continued to deepen due to the gradual increase in the production of AgNPs. A further increase in absorbance with time was not observed, which indicated complete conversion to nanoparticles within $72 \mathrm{~h}$. A similar finding was observed by ourgroup for the green synthesis of AgNPs by different extract[22]. A number of available reports showing absorbance in the range 400-480 nm for AgNPs synthesized using green methods[21,23] additionally support our observation. From the UVvis spectral and visual observation it was clear that rice husk extract is effective for the reduction of silver ions producing AgNPs at room temperature.

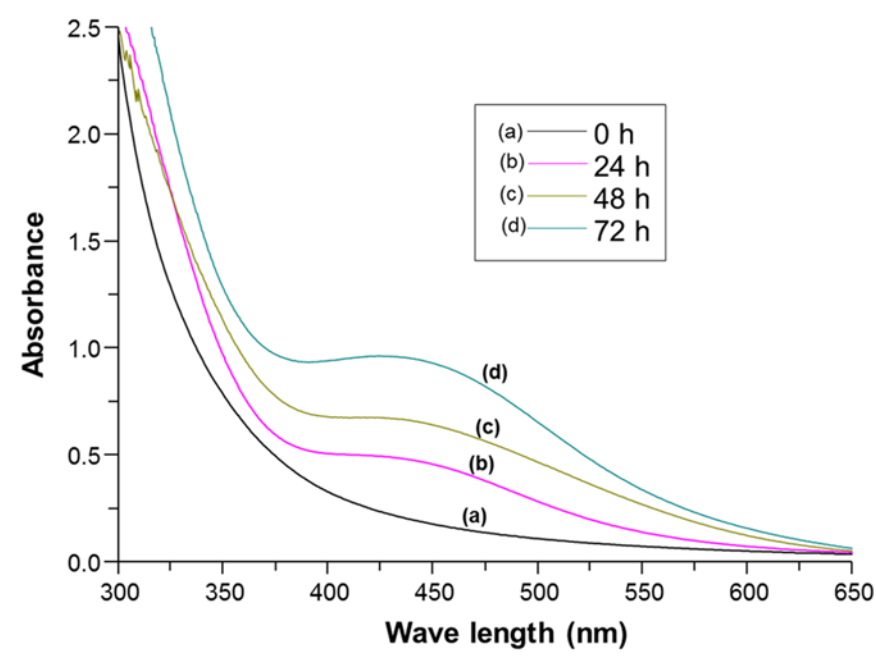

Figure 2. UV-Vis absorption spectra of mixture of aqueous PVA and $\mathrm{AgNO}_{3}$ and rice husk extract at (a) $0 \mathrm{~h}$ (b) $24 \mathrm{~h}(\mathrm{c}) 48 \mathrm{~h}(\mathrm{~d}) 72 \mathrm{~h}$.

To further confirm the morphology of formed AgNPs, TEM analysis was performed and the result is presented in Figure 3. Micrograph revealed spherical or mostly spherical shaped nanoparticles with size in the range 6 - $25 \mathrm{~nm}$ (Figure 3) which agrees to the shape of SPR band in the UV-visible spectrum. Further, the nanoparticles were found to be welldistributed with almost no aggregation as shown in Figure 3. These observations suggest that PVA could effectively stabilize the AgNPs based on the matrix effect.

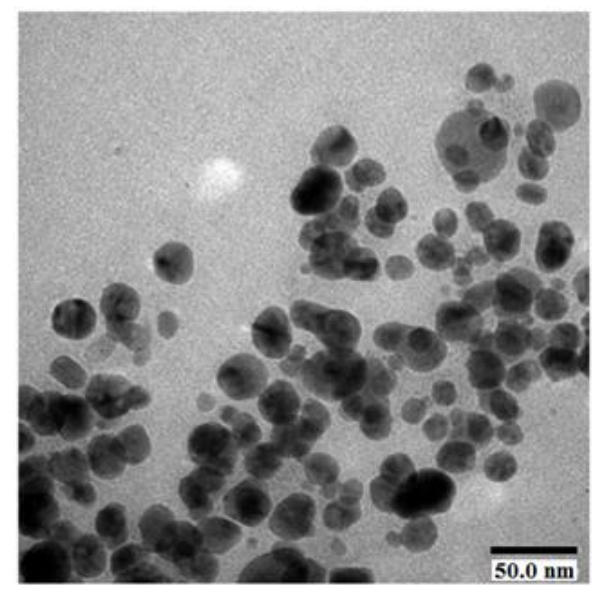

Figure 3. TEM image of synthesized AgNPs embedded in PVA.

The antibacterial activity of rice husk extract mediated PVA-AgNPs hybrid solution was tested against gram-negative (E. coli) and gram-positive (Bacillus sp.) strains. The results clearly showed the obvious inhibitory effect of hybrid on the bacterial growth, as indicated by 
the diameter of inhibition zones in figure 4. As a control, rice husk extract mixed with PVA exhibited no inhibition zone against both tested strains (Figure 4). This suggested that the antibacterial activity was due to the presence of AgNPs in the hybrid. Numerical values of diameter of inhibition zones achieved from this study were summarized in Table 1. Thus, AgNPs-PVA hybrid solution displayed remarkable bacterial inhibition capability, which is in good agreement with our previous report[22].

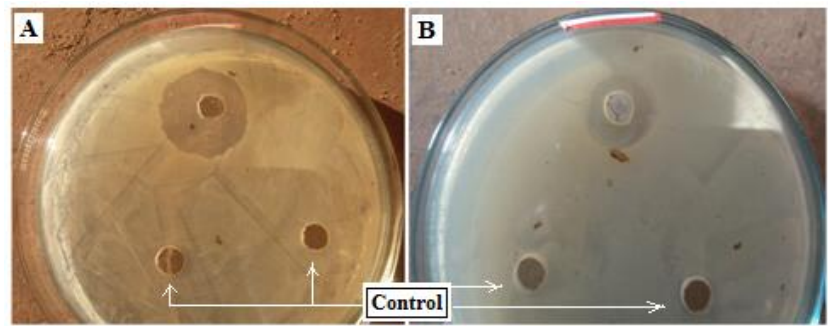

Figure 4. Antibacterial activity assay of PVA-AgNPs hybrid solution against (A) Bacillus sp. and (B) E. coli.

Table 1. Inhibition zones for antibacterial assay of Figure 4.

\begin{tabular}{c|c|c}
\hline \multirow{2}{*}{ Components } & \multicolumn{2}{|c}{ Inhibition zone (mm) } \\
\cline { 2 - 3 } & Bacillus Sp. & E. coli \\
\hline PVA-AgNPs hybrid & $22 \pm 1.0$ & $15 \pm 1.0$ \\
\hline Control (PVA + Rice husk extract) & NI & NI \\
\hline NI: No inhibition
\end{tabular}

\section{Conclusions}

The present study demonstrates a green approach to synthesize PVA-AgNPs hybrid using the extract of rice husk as agricultural waste. Various phytochemicals in rice husk play the role of bio-reductant for the preparation of AgNPs. The approach appears to be very simple, reliable, cost-effective and eco-friendly alternative to conventional physical and chemical methods. The green synthesized AgNPs in the hybrid were characterized by different techniques including UV-vis spectroscopy, and transmission electron microscopy (TEM). The TEM result revealed that AgNPs were roughly spherical shaped with sizes ranged from 6 to 25 nm. PVA-AgNPs hybrid exhibited good antibacterial efficacy against the selected grampositive (Bacillus sp.) and gram-negative ( E. coli) bacterial strains. The use of PVA appears to be a biocompatible stabilizer for produced AgNPs, which is more likely to promote the application of resultant hybrid in biomedical science as a kind of antibacterial material. Further study is under progress in our laboratory.

\section{Funding}

This research received no external funding.

\section{Acknowledgments}

This research has no acknowledgments.

\section{Conflicts of Interest}

The authors declare no conflict of interest. 


\section{References}

1. Kim, Y.H.; Lee, D.K.; Cha, H.G.; Kim, C.W.; Kang, Y.S. Synthesis and characterization of antibacterial Ag-SiO ${ }_{2}$ nanocomposite. J. Phys. Chem. C. 2007, 111, 3629-3635, https://doi.org/10.1021/jp068302w.

2. Natarajan, K.;Selvaraj, S.;Ramachandra, M.V. Microbial production of silver nanoparticles. Dig. J. Nanomater. Bios. 2010, 5, 135-140, https://doi.org/10.1186/2228-5326-2-32.

3. Iravani, S.;Korbekandi, H.;Mirmohammadi, S.V.;Zolfaghari, B. Synthesis of silver nanoparticles: chemical, physical and biological methods. Res. Pharm. Sci.2014, 9, 385-406.

4. Allafchian, A.R.;Mirahmadi-Zare, S.Z.;Jalali, S.A.H.;Hashemi, S.S.;Vahabi, M.R. Green synthesis of silver nanoparticles using phlomis leaf extract and investigation of their antibacterial activity. J. Nanostruct. Chem. 2016, 6, 129-135, https://doi.org/10.1007/s40097-016-0187-0.

5. Patil, M.P.; Singh, R.D.;Koli, P.B.;Patil, K.T.;Jagdale, B.S.;Tipare, A.R.; Kim, G.D. Antibacterial potential of silver nanoparticles synthesized using Madhucalongifolia flower extract as a green resource. Microb. Pathog. 2018, 121, 184-189, https://doi.org/10.1016/j.micpath.2018.05.040.

6. Choi, O.; Deng, K.K.; Kim, N.J.; Ross, L. Jr.;Surampalli, R.Y.; Hu, Z. The inhibitory effects of silver nanoparticles, silver ions, and silver chloride colloids on microbial growth. Water Res. 2008, 42, 3066-3074, https://doi.org/10.1016/j.watres.2008.02.021.

7. Prabhu, S.;Poulose, E.K. Silver nanoparticles: mechanism of antimicrobial action, synthesis, medical applications, and toxicity effects. Int. Nano. Lett. 2012, 2, 1-10, https://doi.org/10.1186/2228-5326-2-32.

8. Franci, G.; Falanga, A.; Galdiero, S.; Palomba, L.; Rai, M.; Morelli, G.; Galdiero, M. Silver Nanoparticles as Potential Antibacterial Agents. Molecules. 2015, 20, 8856-8874, https://doi.org/10.3390/molecules20058856.

9. Sánchez-López, E.; Gomes, D.; Esteruelas, G.; Bonilla, L.; Lopez-Machado, A.L.; Galindo, R.; Cano, A.; Espina, M.; Ettcheto, M.; Camins, A.; Silva, A. M.; Durazzo, A.; Santini, A.; Garcia, M. L.; Souto, E. B. Metal-Based Nanoparticles as Antimicrobial Agents: An Overview. Nanomaterials. 2020, 10, 292 - 330 , https://doi.org/10.3390/nano10020292.

10. Abdel-Mohsen, A.M.; Hrdina, R.; Burgert, L.; Abdel, R.M.; Rahman, M.; Hasova, D.; Smejkalova, M.; Kolar, M.;Pekar, M.; Aly, A.S. Antibacterial activity and cell viability of hyaluronan fiber with silver nanoparticles. Carbohydr. Polym. 2013, 92, 1177-1187, https://doi.org/10.1016/j.carbpol.2012.08.098.

11. Bernabo, M.;Pucci, A.;Galembeck, F.; de Paula Leite, C.A.; Ruggeri, G. Thermal- and Sun-Promoted Generation of Silver Nanoparticles Embedded into Poly(vinyl alcohol) Films. Macromol.Mater. Eng. 2009, 294, 256-264, https://doi.org/10.1002/mame.200800330.

12. Bonilla, A.M.;García, M.F. Polymeric materials with antimicrobial activity. Prog. Polym. Sci. 2012, 37, 281339, https://doi.org/10.1016/j.progpolymsci.2011.08.005.

13. Plaza, H. Antimicrobial polymers with metal nanoparticles. Int. J. Mol. Sci. 2015, 16, 2099-2116, https://doi.org/10.3390/ijms16012099.

14. Paino, M.A.; Bonilla, A.M.;García, M.F. Antimicrobial Polymers in the Nano-World. Nanomaterials. 2017, 7, https://doi.org/10.3390/nano7020048.

15. Gorup, L.F.; Neto, F.N.S.; Kubo, A.M.; Souza, J.A.S.; Fernandes, R.A; Fernandes, G.L.; Monteiro, D.R.; Barbosa, D.B.; Camargo, E.R. Nanostructured Functional Materials: Silver Nanoparticles in Polymer for the Generation of Antimicrobial Characteristics. In: Recent Advances in Complex Functional Materials. Longo, E.; La Porta, F. (eds) Springer, 2017; pp. 271-292, https://doi.org/10.1007/978-3-319-53898-3_11.

16. Huang, X.; Bao, X.; Liu, Y.; Wang, Z.; Hu, Q. Catechol-Functional Chitosan/ Silver Nanoparticle Composite as a Highly Effective Antibacterial Agent with Species-Specific Mechanisms. Sci. Rep. 2017, 7, 1860, https://doi.org/10.1038/s41598-017-02008-4.

17. Ahmed, S.; Ahmad, M.; Swami, B.L.;Ikram, S. A review on plants extract mediated synthesis of silver nanoparticles for antimicrobial applications: A green expertise. J. Adv. Res. 2016, 7, 17-28, https://doi.org/10.1016/j.jare.2015.02.007.

18. Fajar,M.N.; Endarko, E.; Rubiyanto, A.; Malek, N.A.N.N.; Hadibarata, T.; Syafiuddin, A. A green deposition method of silver nanoparticles on textiles and their antifungal activity. Biointerface Res. Appl. Chem. 2020, 10, 4902-4907, https://doi.org/10.33263/BRIAC101.902907.

19. Gandham, R.G.; Raji. P.; Rohan D.B.; Kumar, M.D.; Sharma, V.K.; Keerthana, D.; Karishma, S.; Iyappan, P.; Thirumurugan. R.; Samrot, A.V.; Ponnaiah, P.; Pattammadath, S.; Purayil, S.K.; Javad, P.T.M.; Prakash, P. Green synthesis and antibacterial activity of silver nanoparticles from the aqueous extracts of Cassia alata. Lett. Appl. NanoBioScience. 2020, 9, 1037-1041, https://doi.org/10.33263/LIANBS92.10371041.

20. Genieva, S.D.; Turmanova, S.C.;Dimitrova, A.S.;Vlaev, L.T. Characterization of rice husks and the products of its thermal degradation in air or nitrogen atmosphere. J. Therm. Anal. Calorim. 2008, 93, 387-396, https://doi.org/10.1007/s10973-007-8429-5.

21. Liu, Y.S.; Chang, Y.C.; Chen, H.H. Silver nanoparticle biosynthesis by using phenolic acids in rice husk extract as reducing agents and dispersants. J. food drug.Anal. 2018, 26, 649-656.

22. Mandal, P.; Ghosh, S. Green synthesis of poly(vinyl alcohol)-silver nanoparticles hybrid using Palash (Buteamonosperma) flower extract and investigation of antibacterial activity Polym. Bull. 2018, 75, 19491955, https://doi.org/10.1007/s00289-017-2137-5. 
23. Velusamy, P.; Das, J.; Pachaiappan, R.; Vaseeharan, B.; Pandian, K. Greener approach for synthesis of antibacterial silver nanoparticles using aqueous solution of neem gum (Azadirachtaindica L.). Ind. Crop. Prod. 2015, 66, 103-109, https://doi.org/10.1016/j.indcrop.2014.12.042. 